\title{
IS FOREST LANDSCAPE PATTERN MORE AFFECTED IN ROAD OVERLAP ZONE: EVIDENCE FROM AN UPSTREAM AREA OF THE MINJIANG RIVER OF FUJIAN PROVINCE IN THE SUB- TROPICAL REGION OF CHINA
}

\author{
LIN, Y. Y. ${ }^{1,2,3}-$ HU, X. S. ${ }^{4 *}-$ LIN, M. S. ${ }^{2}-$ QIU, R. Z. ${ }^{4}-$ LIN, J. G. ${ }^{5}-$ LI, B. Y. ${ }^{3 *}$ \\ ${ }^{1}$ Postdoctoral Research Station of Ecology, Fujian Normal University, Science and \\ Technology Road, 350117 Fuzhou, P.R. China \\ ${ }^{2}$ College of Tourism, Fujian Normal University, Science and Technology Road, 350117 Fuzhou, \\ P.R. China \\ ${ }^{3}$ School of Geographical Sciences, Fujian Normal University, Science and Technology Road, \\ 350117 Fuzhou, P.R .China \\ ${ }^{4}$ College of Transportation and Civil Engineering, Fujian Agriculture and Forestry University, \\ Xiyuangong Road, 350108 Fuzhou, Fujian, P.R. China \\ ${ }^{5}$ College of Material Engineering, Fujian Agriculture and Forestry University, Xiyuangong \\ Road, 350108 Fuzhou, Fujian, P.R . China \\ *Corresponding authors \\ e-mail:xshu@fafu.edu.cn; byli985@126.com \\ (Received $3^{\text {rd }}$ Jan 2020; accepted $24^{\text {th }}$ Mar 2020)
}

\begin{abstract}
Despite there is a rich literature base that strives to characterize and understand the influencing factors of landscape ecology, the fact that we still know very little about the ecological impact in the road overlap areas. Taking the upstream area of the Minjiang River of Fujian Province in China, as a case, quantitative landscape metrics were employed to analyze the forest landscape fragmentation and degradation associated with road networks in five zones, including the whole landscape (WL), non-road effect zone (NREZ), road effect zone (REZ), mono-road effect zone (MONREZ) and multi-road effect zone (MULREZ). Our findings showed that $5.4 \%$ of the forest landscape within the REZ experienced changes from 2007 to 2015 , while only $4.1 \%$ in the NREZ. Landscape metrics also identified more scattered habitats in the REZ than in the NREZ. As a result, these leaded to more severe forest landscape degradation in the REZ. Notably, the outcomes showed that the landscape pattern in the MULREZ has been more affected by road networks than the REZ and the MONREZ. Furthermore, the growing rate of landscape degradation from 2007 to 2015 in the REZ was about 1.2 times higher of the NREZ.
\end{abstract}

Keywords: sub-tropical forest, road effect zone, fragmentation, landscape degradation index, landscape pattern

\section{Introduction}

As the element of social development and economic prosperity, road networks tend to occupy a growing percentage of land surface worldwide (Gutiérrez and Urbano, 1996; Wang et al., 2007; Patarasuk, 2013). Development of road network increases accessibility and mobility, meanwhile opening land for resource extraction and other human activities, thus aggravating human interference on ecosystems (Jaeger et al., 2007; Selva et al., 2011). This negative impact on the environment may occur at multiple spatial scales from local to global (Forman, 1998; Coffin, 2007). At the local scale, individual road segment change the ecological process of the landscape, resulting 
in the increased abundance of invasive species, alternating hydrologic flows, and blocking the movement for animals (Forman, 1998). At the landscape scale, road network causes habitat fragmentation and degradation by creating high contrast linear edges, removing, alternating or subdividing the continuous forests into pieces (Hawbaker et al., 2005; Mehdipour et al., 2019). Moreover, landscape speeding changes associated with road network extensions often aggravate habitat fragmentation and degradation (Liu et al., 2014). However, most researches on the effects of roads on ecosystems have examined them at separate scales, few studies have integrated multiple scales in their observation. At the local scale, previous studies have focused on biodiversity conservation, such as traffic mortality, animal movement patterns, species distributed patterns, and species invasion (Spooner et al., 2004; Gibbs and Steen, 2010; Bordadeágua et al., 2011). At the landscape level, landscape structure, pattern and cover change dynamics have been quantified using geographical information system (GIS) tools. Considering the complexity and irreversibility due to the cumulative and timelagged effects of road network on biodiversity (Selva et al., 2011), conservation evaluations on a local scale are far from comprehensive due to the lack of related knowledge (e.g. the habitats' alternations or forest displacement), while landscape-level analyses, such as landscape transitions, often have limited ecological meanings for biodiversity, owing to number of land cover classes restricted by satellite imagery (Wimberly and Ohmann, 2004; Fu et al., 2010; Li et al., 2010). For example, typical analysis of road effect on landscape pattern based on previous studies usually does not distinguish among forest categories, instead they view on "forests" as an implicitly homogenous category, thereby ignoring variations between forests and their effects on the ecological processes (Wang et al., 2007; Patarasuk, 2013; Angelstam et al., 2017). Only a few of studies on road disturbances subdivided forests into coniferous forest, mixed forest and broad-leaved forest (Freudenberger et al., 2013; Liang et al., 2014). Fortunately, the implement of Forest Resources Inventory Program in China involves an intensive survey of permanent sampling plots, thus establishing an extensive database covering many aspects of the forest resources at the biome level, such as forest type, and tree species type (Ren et al., 2011; Xie et al., 2011). This large database provides an excellent and unique opportunity to assess forest composition at the finer level. In this study, we classified landscape into relatively homogeneous forest types to address the environmental heterogeneity across the region basing on the dominant tree species (group) at the patch level, then relating patterns of forest change with road network. This combining the biome level (sampling plots) with the patch level (spatial information) datasets in an analysis of forest landscape structure overcomes the deficiencies of local-scale empirical studies and landscape-scale studies separately (Redo et al., 2012).

Although biodiversity exists at the multiple levels (e.g. genetic, species, population, community, ecosystem, and landscape level) (Lindenmayer et al., 2000), all levels of biodiversity could be enhanced from improved connectivity and stability of forest from a landscape-level perspective (Forman, 1998). In this context, landscape structure, fragmentation and connectivity should be included into the biodiversity indicator system (Liu et al., 2014; Karadağ and Şenik, 2019), e.g., the efficiency of biodiversity conservation is often assessed by landscape metrics representing the spatial structure in a quantitative manner (Sowińska-Świerkosz and Soszyński, 2014). Such landscape metrics consist of a set of indexes at the patch, class and landscape levels, which are always calculated for both administrative borders (Hargis et al., 1998) and for different 
kinds of natural units, such as a park (Peng, 2019) or a watershed (Syrbe and Walz, 2012). They are also used to suggest the level of anthropogenic interference in landscape (Moser et al., 2007).

Habitat fragmentation and the subsequent effects of roads have been widely studied in America (Airey, 1992; Mcgarigal et al., 2001; Forman et al., 2002) and Europe (Jaeger et al., 2007; Freudenberger et al., 2013; Psaralexi et al., 2017), while similar research has just begun in China (Forman et al., 2002; Li et al., 2010). Since the implementing of the government's reform policy, China's road network construction has made brilliant achievements during the past four decades. As one of the most developed regions in China, Fujian Province also experienced rapid development in the construction of road infrastructure during 2007 and 2015, and in the coming years, more roads will be built to improve the accessibility for the region according to the provincial strategic plan. Moreover, Fujian Province is also one of the four major forest regions in China, with the highest forest coverage rate $(66.8 \%, 2018)$ in the country (http://lyt.fujian.gov.cn/). It is noteworthy that a recent study indicated that active transformations occur among forest cover types with high conversion rates (e.g. from primary and secondary forest to planted forests) in this region (Zhang et al., 2010; Hansen et al., 2014), which can lead to the reduction of forest biodiversity and carbon storage of forest biomass (Carnus et al., 2006; Stephens and Wagner, 2007). Therefore, the direct and underlying driving forces of such landscape dynamics need to be further investigated in the upcoming studies to habitat conservation (Zhang et al., 2010). Especially, with the expansion of the road network, more and more roads are built parallelly, e.g., parallel roads of different levels are very common here; moreover, the numbers of road intersections increase greatly. These both lead to the overlapping and overlapping road effect zones. However, quantitative research on the impact of these zones on the landscape is still lacking. Thus, researches on the ecological effects of road network, especially of road overlap areas, on the forest landscape structure and degradation will have significant practical applications for this region.

Taking a typical forest landscape in the sub-tropical region, the upstream area of the Minjiang River, Fujian Province, as a case, we hypothesized five zones in this paper firstly, including the whole landscape (WL), non-road effect zone (NREZ), road effect zone (REZ), mono-road effect zone (MONREZ) and multi-road effect zone (MULREZ). Then, different rates and trajectories of forest cover changes among these zones were compared in this study. Specified, the objectives are: (1) investigate the effects of the road network on forest landscape structures (habitat fragmentation, connectivity and heterogeneity) in the five zones; (2) comprehensively evaluate the forest landscape degradation dynamics in the five zones by a comprehensive index (landscape degradation index, LDI); (3) examine whether the 'scaling up' level of human disturbance on ecosystems exists in the MULREZ zones.

\section{Materials and methods}

\section{Study area}

The study area, the upstream area of the Minjiang River $\left(26^{\circ} 5^{\prime} \mathrm{N}, 117^{\circ} 5^{\prime} \mathrm{E}\right)$ is in a catchment basin between the Wuyi Mountains and the Daiyun Mountains, the skeletons of the terrain in Fujian Province, China. The area belongs to a typical sub-tropical forest. In the study area, $82.7 \%$ of the land area was covered by forest in 2007 and was selected as the study site, with total area of $672 \mathrm{~km}^{2}$. Three reasons make it suitable for 
this study: (1) intensive extensions of road network in recent years, e.g. Quan-Shan and Yong-Ning express ways, have enforced biodiversity in this region to be subjected to severe disturbances by these roads; (2) this area is located in the upper reaches of the Minjiang River, therefore, the water quality of these rivers highly depends on the protection the forests in the study area; (3) the mixed forest with Chinese fir, pine and hardwood is a major type in the southeastern China, and of national and international importance in terms of its provision of both plant diversity and community stability of the ecosystem.

\section{Data sources}

The road data was digitized as a vector map based on the transportation maps of Sanyuan District in 2015. According to the study by Liu et al. (2008) the roads were divided into six categories (Fig. 1a): (1) first level (expressway), (2) second level (national roads), (3) third level (provincial road), (4) fourth level (county road), (5) fifth level (country road) and (6) sixth level (the other main road).

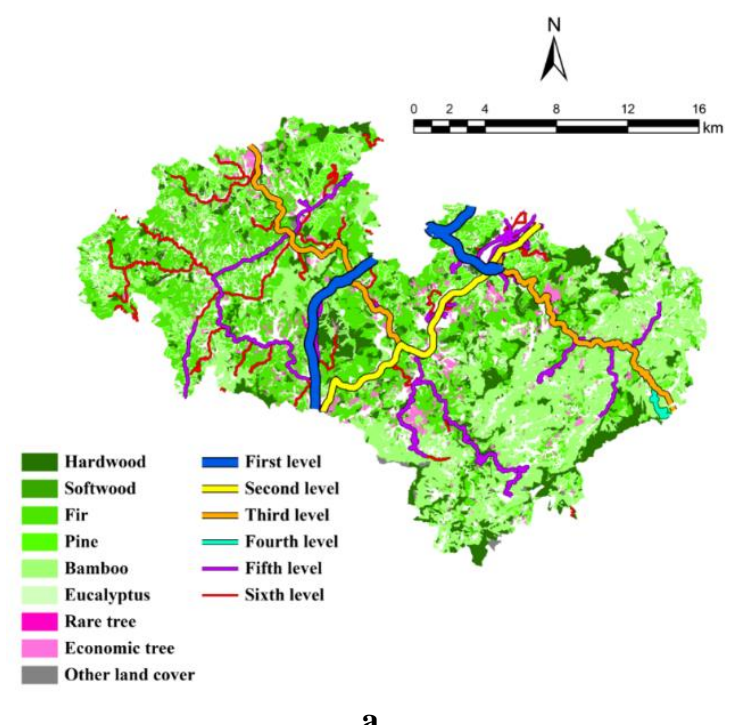

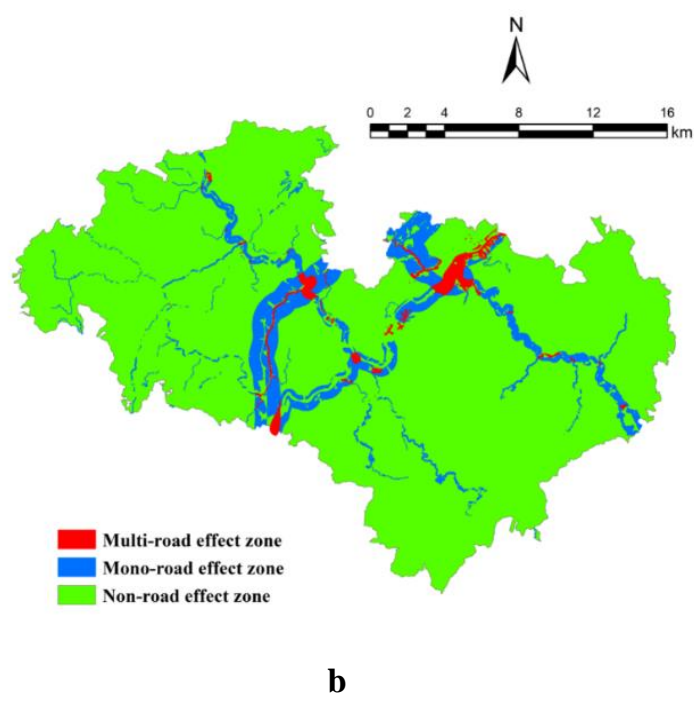

b

Figure 1. (a) Road network of study area, (b) study zones, including multi-road effect zone (MULREZ), non-road effect zone (NREZ), mono-road effect zone (MONREZ), road effect zone (REZ) is composed of MONREZ and MULREZ, and whole landscape (WL) is composed of NREZ and REZ

The forest landscape maps were derived from Forest Resources Inventory Databases (vector maps) for 2007 and 2015, collected from the local forestry department. In China, the database is the second type of forest resource survey based on forest management units such as state-owned forest farms, nature reserves, forest parks, or county-level administrative areas, to meet the needs of forest management plans, overall design, forestry zoning, and planning and design. The outcome of the survey is the establishment and update of forest resource inventory database, which is the basis for forestry engineering planning and design and forest resource management, is also an important basis for formulating regional national economic development plans and forestry development plans, implementing forest ecological benefit compensation and 
forest resource asset management, and guiding and standardizing forest scientific management. The database is prepared and updated yearly by the combining of field investigation (Fig. 2) and remote sensing. Sample plots systematically located on 1-by$1 \mathrm{~km}$ grid cells across the study area and are used for remote sensing verification as well (see (Xie et al., 2011) for detail). The database provides miscellaneous information at the landscape pixel level, such as land type, terrain factors, vegetation type, and dominant tree species so on.

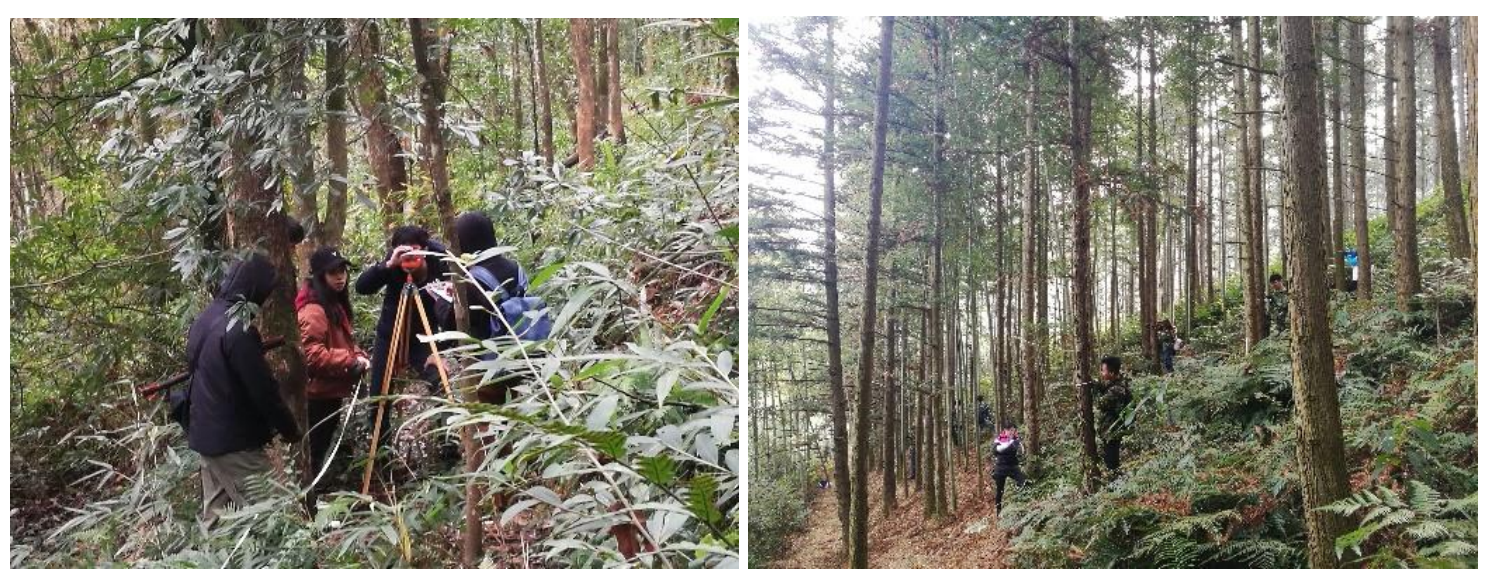

Figure 2. Field investigation

\section{Landscape classification}

In this study, we classified the forests into nine categories according the dominant tree species (i.e., with the highest percentage in quantity of all individuals) of each biome when mapping forest landscapes. The nine categories of forests were fir, pine, rare tree, softwood, hardwood, Eucalyptus, bamboo, economic tree and other land cover (Table 1). Then, transitions between forest cover categories between 2007 and 2015 were calculated using area tabulation tool of ArcGIS software for each studied zone.

\section{Definition of road effect zones and zones}

The first-, second-, third-, fourth-, fifth- and six-level roads were buffered at $1000 \mathrm{~m}$, $500 \mathrm{~m}, 250 \mathrm{~m}, 100 \mathrm{~m}, 50 \mathrm{~m}$ and $25 \mathrm{~m}$, respectively, depending on the impact degree on the ecosystems (Wang et al., 2007; Liu et al., 2014). A minor portion of buffer zones of different level roads overlapped each other. Theoretically, these overlapped areas are more accessible than others, with more chances to be interrupted. In this context, it is interesting to better understand several fundamental questions. Are these areas more vulnerable? Is the 'scaling up' level of human disturbance on ecosystems in these areas higher than that of the other? To answer these questions, the road effect zone was separated into mono-road effect zone and multi-road effect zone here, thus as a whole five zones were hypothesized in this study, including WL $\left(672 \mathrm{~km}^{2}\right)$, NREZ $\left(607 \mathrm{~km}^{2}\right)$, REZ $\left(65 \mathrm{~km}^{2}\right)$, MONREZ $\left(62 \mathrm{~km}^{2}\right)$ and MULREZ $\left(3 \mathrm{~km}^{2}\right)$ (Fig. 1 b). Then, landscape metrics for these five zones were calculated respectively for the comparisons of their Landscape change, habitat fragmentations, isolation, heterogeneity and landscape degenerations between 2007 and 2015. 
Table 1. Description of the nine classes of forest cover

\begin{tabular}{|c|c|c|}
\hline $\begin{array}{l}\text { Forest cover } \\
\text { classes }\end{array}$ & Classification criteria & Biomes \\
\hline Fir & Taxodiaceae family species & Cunninghamia lanceolata \\
\hline Pine & Pinaceae family species & $\begin{array}{c}\text { Pinus massoniana, } P \text {. elliottii, } P . \\
\text { taeda, Tsuga chinensis var. } \\
\text { tchekiangenesis }\end{array}$ \\
\hline Rare tree & $\begin{array}{c}\text { The first reference list of the main rare } \\
\text { species in Fujian Province (2007), compiled } \\
\text { by the Fujian Province Department of } \\
\text { Forestry }\end{array}$ & $\begin{array}{c}\text { Cinnamomum camphora, Phoebe } \\
\text { bournei, Fokienia hodginsii, } \\
\text { Taiwania cryptomerioide, } \\
\text { Liquidamba formosana, Cryptomeria } \\
\text { fortunei }\end{array}$ \\
\hline So & \multirow[b]{2}{*}{$\begin{array}{l}\text { Hard timber trees, are generally more durable } \\
\text { and denser than softwoods or soft timbers } \\
\text { although not all are harder than softwoods the } \\
\text { main differences between them are botanical, } \\
\text { these types of trees have broader leaves than } \\
\text { soft timber trees }\end{array}$} & Paulownia chinense \\
\hline Hardwood & & Castanopsis species, Schima superba \\
\hline Eucalyptus & Plants of Eucalyptus (Myrtaceae family) & Eucalyptus grandis, E. citriodora \\
\hline Bamboo & The woody bamboos & $\begin{array}{c}\text { Phyllostachys edulis, Dendrocalamus } \\
\text { olhami, D. latiflorus }\end{array}$ \\
\hline Economic tree & $\begin{array}{c}\text { Those where the main management emphasis } \\
\text { is on forest products rather than timber, such } \\
\text { as fruit, bark, leaves, tree sap, branches, } \\
\text { flower buds and tender sprouts }\end{array}$ & $\begin{array}{c}\text { Citrus maxima, } C \text {. reticulate, } C . \\
\text { mollissima, Camellia oleifera, } C . \\
\text { Sinensis, Magnolia officinalis, } \\
\text { Vernicia fordii }\end{array}$ \\
\hline Other land cover & \begin{tabular}{|c|} 
Other forest covers apart from the above, \\
besides which non-forest covers are included \\
in this category in the 2015's landscape
\end{tabular} & $\begin{array}{l}\text { 2007: shrub land and minor forest; } \\
\text { 2015: shrub land, minor forest, no } \\
\text { standing forest and non-forest }\end{array}$ \\
\hline
\end{tabular}

\section{Calculation of landscape change rate}

Landscape change rate (LCR) indicates the transfer rate between all landscape types in a study period in a region, and can be used to characterize the intensity of landscape type transformation in a particular region (e.g., a road buffer zone) in order to find a hot spot for change. It can be calculated as follows (Eq. 1):

$$
L C R=\frac{\sum_{i=1}^{n} \Delta L A_{i-j}}{\sum_{i=1}^{n} L A_{i}} \times 100
$$

where, $L C R$ is the landscape change rate $(\%)$ of the integrated landscape during the study period, $L A_{i}$ is the total area of the initial landscape type $i, \Delta L A_{i-j}$ s the area of landscape type $i$ converted to the landscape type $j$ during the study period.

\section{Calculation of landscape degradation}

The Fragstats software presents the most comprehensive overview of the landscape metrics, which are algorithms that quantify the specific spatial characteristics of three hierarchical levels: patch level, class level and landscape level (Šímová and Gdulová, 2012). To investigate the effects of road network extensions on landscape structure, we measured commonly used landscape metrics to analyze the habitat changes for each landscape using the Fragstats 3.4 program (Mcgarigal and Marks, 1995; Mcgarigal et 
al., 2001). Among which, area related indices were calculated to describe the features of patches, such as mean patch area (AREA_MN), standard deviation of patch area (PSSD) and coefficient variation of patch area (AREA_CV). Number of patch (NP), patch density (PD), edge density (ED), and mean fractal dimension index (FRAC_MN) were used to examine habitat fragmentation at the class level. The isolation, connection and heterogeneity of the entire landscape were indicated by landscape level metrics: aggregation index (AI), contagion index (CONTAG) and Shannon's evenness index (SHEI). For the formulas and detailed descriptions of all landscape indices, please refer to reference (Mcgarigal and Marks, 1995; Mcgarigal et al., 2001).

Quantitatively measuring the fragmentation, isolation, connection and heterogeneity of the entire landscape have been extensively applied to the analysis of landscape pattern using landscape metrics (Turner et al., 2003). However, these metrics were calculated as separate indicators in the most of the landscape structure studies (Tinker et al., 1998; Mcgarigal et al., 2001), with little contribution to the comprehensive comparisons of different ecological processes between different landscapes. In this context, an integral index, LDI, was selected to evaluate the landscape pattern as a whole. LDI measures the fragmentation and the stability of the entire landscape, which is proportionally composed of a series of metrics, such as AREA_CV, PD, ED, FRAC_MN, CONTAG, AI and SHEI. The formulas were given by the following expressions (Wang et al., 2007; Eqs. 2-4).

$$
\begin{gathered}
L F D I=a A R E A \_C V+b P D+c E D+d F R A C_{-} M N \\
L S I=\sqrt[3]{C O N T A G \times S H E I \times A I} \\
L D I=L F D I / L S I
\end{gathered}
$$

where the LDI includes landscape fragmentized degree intensity (LFDI) and landscape stability index (LSI); $a, b, c$ and $d$ are the weights of the indexes of AREA_CV, PD, ED, and FRAC_MN, which is $0.27,0.26,0.24$ and 0.23 respectively (Wang et al., 2007).

We assumed that in a region with relatively homogeneous biophysical interference, higher value of LDI indicates higher level of anthropogenic interference (e.g., road network, cutting) in the habitats, which, in turn, influences the abundance and distribution of plant and animal species (Geneletti, 2003; Eigenbrod et al., 2008).

\section{Results}

\section{Forest landscape composition and dynamics in different senarios}

For the whole landscape, NREZ and REZ occupied $90.3 \%$ and $9.7 \%$ of the study area respectively. In the REZ, MONREZ and MULREZ occupied 95.0\% and 5.0\%, respectively (Fig. 3).

Figure 2 also indicated that forest landscape changes were active during the study period in all the zones. 5.4\% of the landscape in the REZ experienced forest cover change between 2007 and 2015. By contrast, only 4.1\% of the landscape in the NREZ was transformed between 2007 and 2015. In the REZ, 5.6\% of the landscape experienced forest cover change in the MONREZ, while it was unexpectedly that only $2.3 \%$ of the landscape was transformed in the MULREZ between 2007 and 2015. 


$$
-3700-
$$

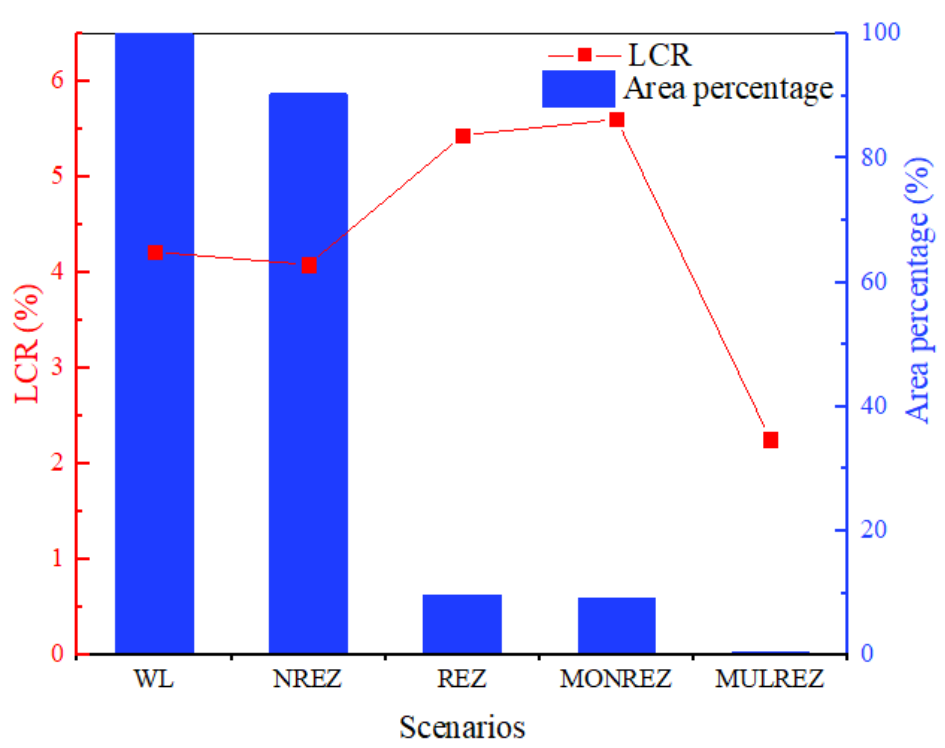

Figure3. Proportion of each zone and its landscape change dynamics. The curve represents the landscape change rate of d different zones (left Y-axis); the columns represent the area proportion of each zone to the total area of the study area (right Y-axis). LCR is landscape change rate

Figure 4 showed the forest landscape compositions and dynamics from 2007 to 2015 for the five zones. The dominant forest cover classes were fir and bamboo, predominating in $34.1 \%$ and $31.7 \%$ in 2007 , and $32.7 \%$ and $31.7 \%$ in 2015 , respectively, in the WL zone. Compared to the NREZ, the REZ had a relatively smaller proportion of bamboo, accounted for $21.5 \%$ and $21.7 \%$ of the area, respectively in 2007 and 2015. On the contrary, the proportion of fir and economic tree in the REZ were about 5\% higher than that in the NREZ in the both years. Furthermore, it was worth to mention that the proportions of other land cover in the REZ (especially in the MULREZ) were uncommonly several-fold beyond those in the NREZ.
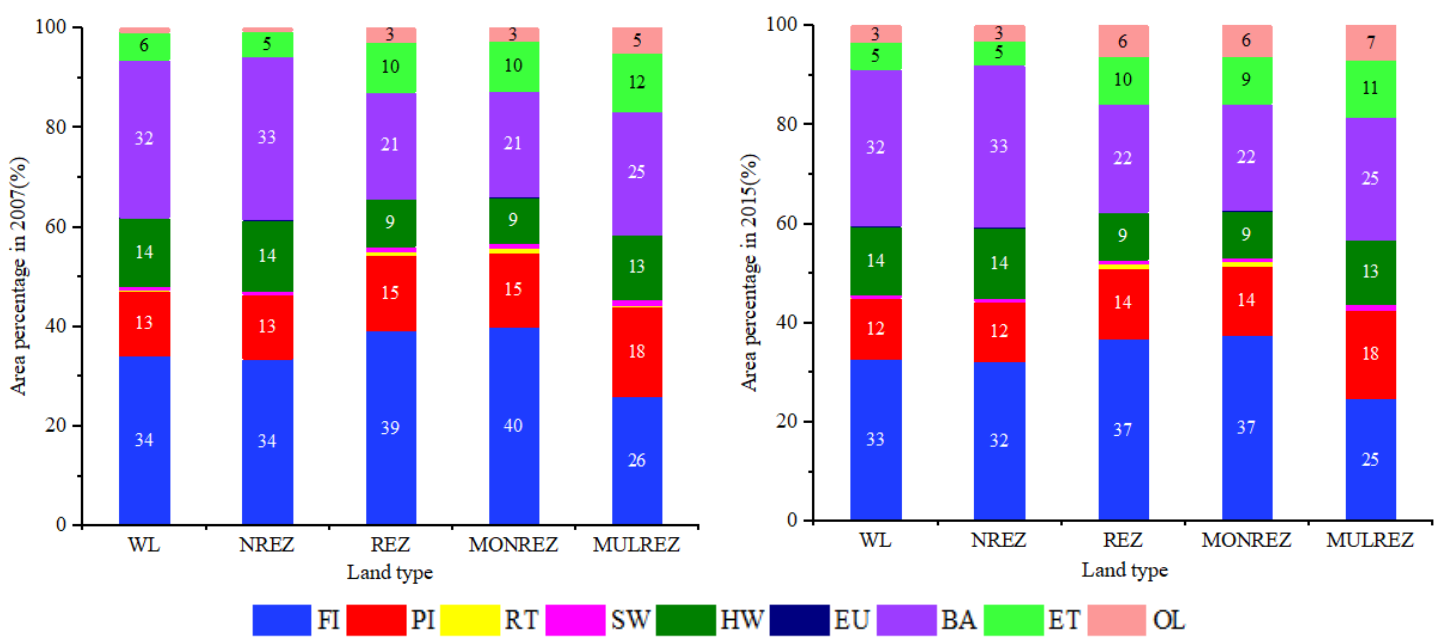

Figure 4. Forest landscape composition in each zone. The nine categories of forests were Fir (FI), Pine (PI), Rare tree (RT), Softwood (SW), Hardwood (HW), Eucalyptus (EU), Bamboo $(B A)$, Economic tree (ET) and other land cover $(O L)$. The numbers on the columns indicates the percentage of each landscape in each zone 
Figure 5 indicated that, in all the zones, bamboo and hardwood showed high stability during the studied period, fir, pine, softwood and economic tree decreased steadily, while eucalyptus and other land cover increased dramatically over time. Between 2007 and 2015, fir in the NREZ was reduced by $4.0 \%$ of its area, while the reduction increased to $6.1 \%$ in the REZ; the proportion of pine was also slightly reduced by $6.7 \%$ and $5.5 \%$ in the NREZ and REZ, respectively. The opposite trend was observed in other land cover, which increased more than four times in the NREZ, whereas, only increased $127.0 \%$ in the REZ. Eucalyptus also increased $22.8 \%$ and $74.2 \%$ in the NREZ and REZ, respectively. Simultaneously, the change of rare tree showed a different trends and directions in different zones. Specifically, in the NREZ zone, the area of rare tree increased, while in the case of road zones (i.e., REZ, MONREZ, MULREZ), the area of rare tree species decreased, especially all the area of rare tree was encroached in the MULREZ zone.

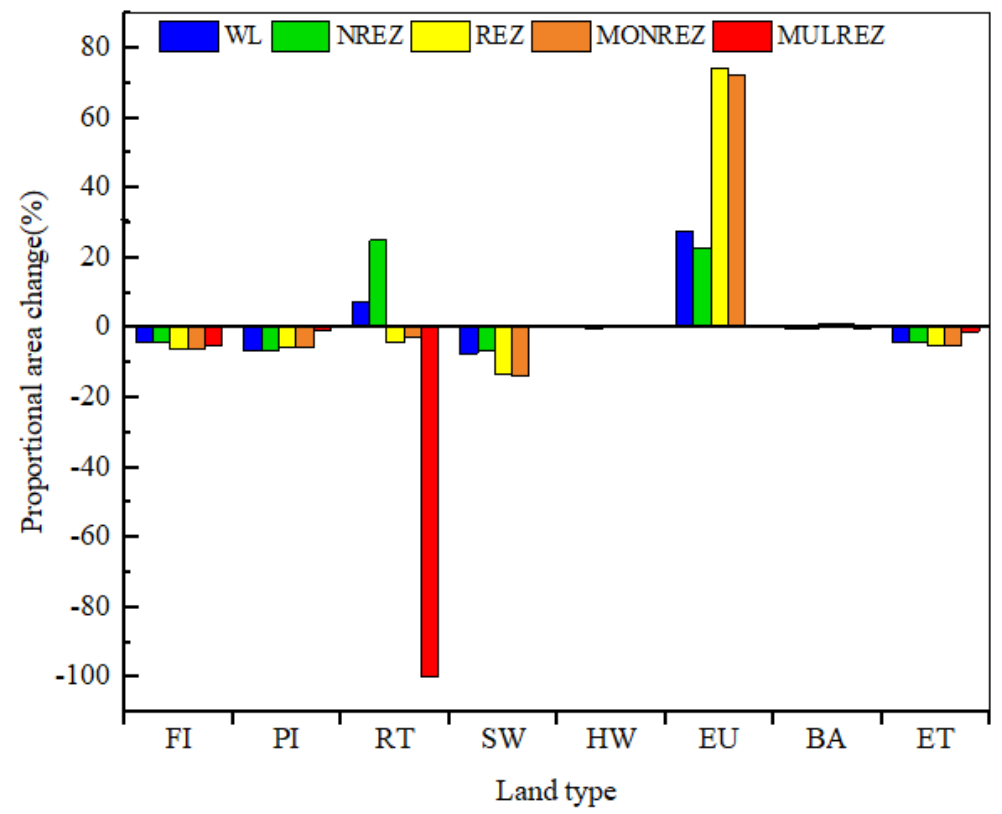

Figure 5. Forest landscape change dynamics in each zone during 2007-2015

\section{Forest landscape patterns and dynamics in different scenarios}

Table 2 showed the calculated results of the landscape metrics for the years of 2007 and 2015. In this studied case, the AREA_MN index in the NREZ (10.853-12.150 ha) was much higher than that of the REZ (2.989-3.215 ha) (P-value $=0.000)$, which indicated that the forest landscape structure of the NREZ was much more stable, and distinguished by a number of larger area patches. The PD index was substantially higher in the REZ (31.102-33.461) than that in the NREZ (8.231-9.214) (P-value =0.000), especially in the MULREZ (80.021-81.571) even ten times or so as much as that in the NREZ (P-value = 0.000). Analogically, the ED index in the REZ (71.410-77.496) was significantly higher than that of the NREZ (57.372-61.697) (P-value $=0.000)$, moreover, MULREZ had a greater ED than the former two as well. These findings clearly indicated that the landscape spatial structure in the REZ (especially in the MULREZ) was much more fragmented than that in the NREZ. 
The AI and CONTAG values were close in all the zones, with the highest in the NREZ, and then in the REZ, followed by the MULREZ. The study results showed that patch types with a similar area (lower AREA_CV and PSSD values) in the REZ were generally much more dispersed than those of the NREZ. The SHEI value was bit higher in the REZ (0.742-0.770) (P-value =0.005), much higher in the MULREZ (0.835$0.843)$ (P-value $=0.000)$ than that in the NREZ $(0.683-0.712)$. This finding confirmed a lower landscape diversity of the REZ than that of the NREZ.

Table 2. Statistics of forest landscape metrics under different zones

\begin{tabular}{c|c|c|c|c|c|c|c|c|c|c|c|c}
\hline Metrics & Year & NP & AREA_MN & PSSD & AREA_CV & PD & ED & FRAC_MN & SHEI & AI & CONTAG & LDI \\
\hline \multirow{2}{*}{ WL } & 2007 & 4607 & 14.562 & 162.124 & 1113.309 & 6.867 & 58.865 & 1.106 & 0.692 & 97.892 & 63.18 & 1.181 \\
& 2015 & 5266 & 12.74 & 112.673 & 884.404 & 7.849 & 63.368 & 1.107 & 0.72 & 97.78 & 61.615 & 1.22 \\
\hline \multirow{2}{*}{ NREZ } & 2007 & 4988 & 12.15 & 90.725 & 746.722 & 8.231 & 57.372 & 1.107 & 0.683 & 97.862 & 63.693 & 1.122 \\
& 2015 & 5584 & 10.853 & 79.467 & 732.205 & 9.214 & 61.697 & 1.108 & 0.712 & 97.756 & 62.105 & 1.193 \\
\hline \multirow{2}{*}{ REZ } & 2007 & 2017 & 3.215 & 10.513 & 326.974 & 31.102 & 71.41 & 1.12 & 0.742 & 96.308 & 60.254 & 1.621 \\
& 2015 & 2170 & 2.989 & 9.461 & 316.565 & 33.461 & 77.496 & 1.119 & 0.77 & 96.159 & 58.634 & 1.742 \\
\hline \multirow{2}{*}{ MONREZ } & 2007 & 2141 & 2.879 & 9.452 & 328.359 & 34.741 & 70.836 & 1.12 & 0.738 & 96.163 & 60.459 & 1.672 \\
& 2015 & 2293 & 2.688 & 8.48 & 315.51 & 37.207 & 77.106 & 1.119 & 0.767 & 96.009 & 58.773 & 1.797 \\
\hline \multirow{2}{*}{ MULREZ Z } & 2007 & 258 & 1.25 & 2.352 & 188.175 & 80.021 & 77.493 & 1.119 & 0.835 & 94.459 & 55.224 & 2.459 \\
& 2015 & 263 & 1.226 & 2.316 & 188.897 & 81.571 & 80.052 & 1.119 & 0.843 & 94.393 & 54.737 & 2.522 \\
\hline
\end{tabular}

Number of patch (NP), mean patch area (AREA_MN), standard deviation of patch area (PSSD), coefficient variation of patch area (AREA_CV), patch density (PD), edge density (ED), mean fractal dimension index (FRAC_MN), aggregation index (AI), contagion index (CONTAG) and Shannon's evenness index (SHEI), landscape degradation index (LDI)

Figure 6 showed that the trends of the landscape metrics between 2007 and 2015 were relatively unanimous in all the zones, indicating a decreasing trend as the increasing intensity of road disturbance, in order of WL, NREZ, MONREZ and REZ and MULREZ.

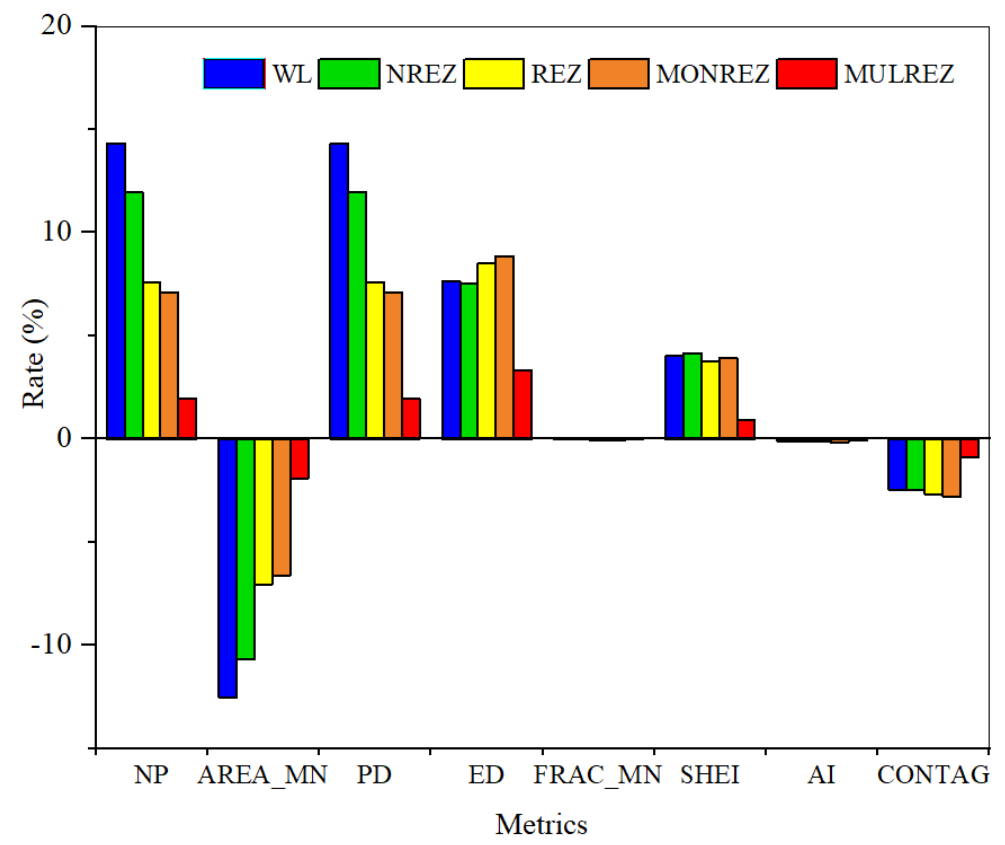

Figure 6. Change rates in landscape metrics in each zone (2007-2015) 


\section{Forest landscape degradation and dynamics in different scenarios}

The dynamics of the landscapes showed that the fragmentations of the landscape structures were obviously strengthened under the disturbance of road network (Table 2). In Figure 7, the composite index of landscape fragmentation (LFDI) also showed that the degree of fragmentation of forest landscape increases with the increase of road disturbance intensity, moreover, the trend was relatively stable for the index of LSI. Referring these results directly to identify the level of degradation of the entire landscape requires the analysis of the LDI. In this case, the LDI was significantly higher in the REZ (1.621-1.742) than that in the NREZ (1.193-1.122), and the MULREZ (2.459-2.522) had much higher LDI than MONREZ (1.672-1.797). Furthermore, the growing rate of landscape degradation from 2007 to 2015 in the REZ was about 1.2 times as that in the NREZ, however, the change rate in the MULREZ was relatively low (Fig. 8). This finding confirms that road networks have broken the landscape into pieces and resulted in fragmented ecosystems and complicated ecosystem structures, eventually accelerating the degradation of the ecosystem.

\section{Discussion}

\section{Landscape transitions}

As a permanent modification of the landscape, road network threatens the existing habitats and the wildlife populations depending on it, e.g., interrupting ecological flows, inhibiting interior species, and promoting landscape fragmentation (Forman, 1998). Landscape fragmentation is a breakup to transform a continuous habitat into smaller, more dispersal patches, which can impose destructive and irreversible consequences on regional biodiversity (Trakhtenbrot et al., 2005). Such negative impacts of road network have been hot topics in the study of landscape ecology and biodiversity conservation (Zhu et al., 2006; Benítez-López et al., 2010). In this study, we detected considerable transitions among different forest landscapes types in each zone. Though landscape dynamics patterns varied through zones, most of the changed forest cover was transformed into other land cover in all the zones. However, the key differences were that the percentages (the area changed to other land cover divided by the total area experienced change in each zone) were significantly higher in the REZ (67.4\%) than that in the NREZ $(60.9 \%$ ) (Table Al in the Appendix). Moreover, the MULREZ was among the most surprising zone, in which more than $80 \%$ of the forest cover change happened to shift into other land cover. In the NREZ, gain of other land cover area was largely from fir, which accounted for more than $60 \%$ of the total area gained by other land cover in the study periods; while, in the REZ, the gain of other land cover was from relatively diversified forest covers, among which fir, pine and economic tree accounted for $38.5 \%, 10.0 \%$ and $8.6 \%$ of the total area gained by other land cover, respectively. All these findings indicated that the forest covers have suffered greater human disturbance in the REZ (MULREZ in particular) than in the NREZ. Previous studies on the ecological impacts of road network at the landscape level, with no effort identifying habitat changes among forest types, which have limited ecological meanings to devise more effective strategies for biodiversity conservation ( $\mathrm{Li}$ et al., 2010; Patarasuk, 2013). In this study, we overcame these difficulties by conducting a Forest Resources Inventory Database-based analysis of changes in forest landscape, stratified 
by dominant species in respective biomes, which it very helpful in identifying the dynamics of forest landscape changes from a finer scale.
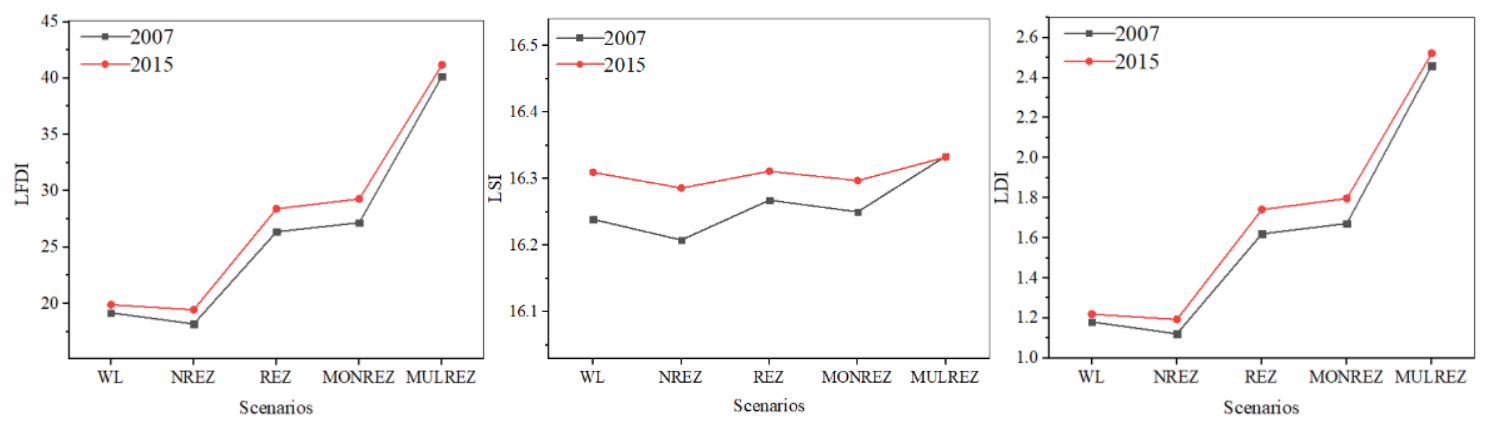

Figure 7. Landscape degradation dynamic in each zone (2007-2015)

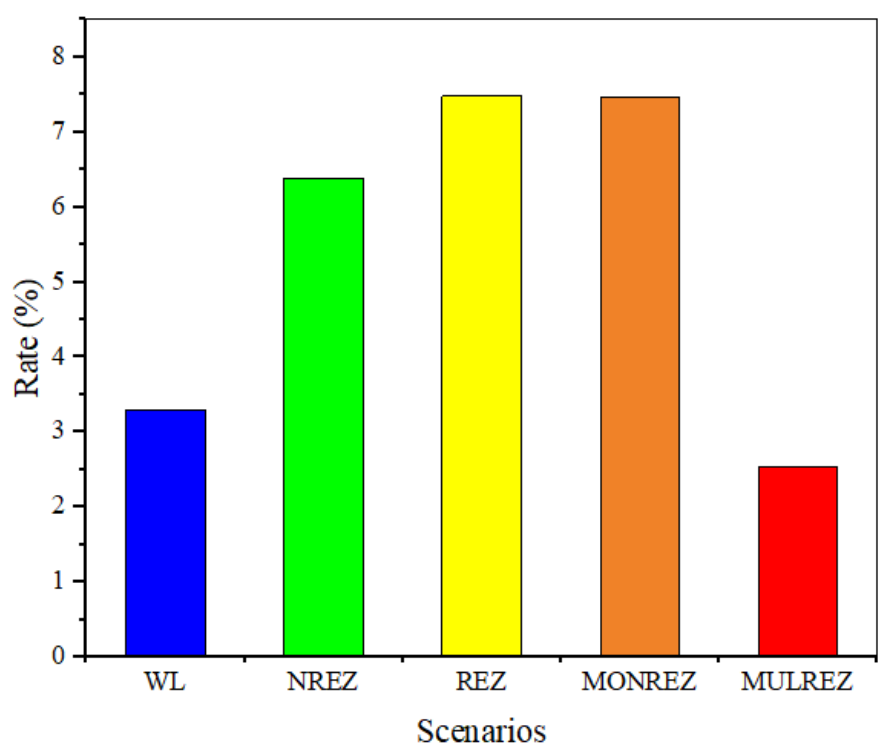

Figure 8. Change rate of landscape degradation index from 2007 to 2015

\section{Landscape degradation}

In our study, it was obvious that the landscape metrics varied greatly across different zones, revealing that the landscape spatial structure in the REZ (especially in the MULREZ) was much more fragmented than that in the NREZ, and a lower landscape diversity in the REZ than that of the NREZ. This finding indicates a higher level of interference imposing on the forests in the REZ, leading to the increasing of habitat fragmentation and isolation, the decreasing of heterogeneity in forest landscape near roads. Our results agree with previous researches, documenting habit fragmentation causing by the changes of landscape patterns near road corridors (Hawbaker et al., 2005; Liu et al., 2008), which have been reported as a contribution to the declining in forest species (Arnold et al., 1995; Mcintyre, 1995). However, different from many of these studies (Heilman et al., 2002; Liu et al., 2014), we further separated the REZ into two segments, i.e., MONREZ and MULREZ. Our result indicated that the level of 
habitat fragmentation and isolation in the MULREZ was much higher than that of the MONREZ, implying that there exists superimposed effect of the roads on the forest landscape.

For the change ratios between 2007 and 2015, landscape fragmentation indices (NP, AREA_MN, PSSD, PD and ED) had larger values than landscape stability index (AI, CONTAG and SHEI). In all the zones except the MULREZ, the rates of change of NP, AREA_MN, PSSD, PD and ED indices were 7.1 14.3\%, 6.6 12.5\%, 10.3 30.5\%, $7.1 \sim 14.3 \%$ and $7.5 \sim 8.9 \%$, respectively, while those for the AI, CONTAG and SHEI indices were $-0.2 \sim-0.1 \%,-2.8 \sim-2.5 \%$ and $3.8 \sim 4.2 \%$, respectively (Table 2). The relatively major changes in landscape fragmentation and relatively minor changes in overall landscape structure of the forest may be attributed to the high rate of persistence in area size of each forest category between 2007 and 2015, while a relatively rapid transition intra/inter- these cover categories occurred. This provided a good reason for us to classify landscape into forest types basing on the dominant tree species.

As landscape fragmentation indices concerned, the change ratios of NP, AREA_MN, PSSD, and PD in the NREZ were higher than those in the REZ, while it was versa for the change ratios of ED. Similarly, the comparisons of the change ratios for landscape stability indices also showed a bidirectional diagram between the NREZ and the REZ. Though, much greater in habitat fragmentation and landscape degradation was evident on the REZ, more significant changes of habitat fragmentation were detected in the NREZ between 2007 and 2015. Also, an unexpected outcome of the study was the lowest change ratios of such indices in the MULREZ. The reasons are followed: the study area has always been a key base of forestry industry in Fujian Province, a large proportion of forest is designated as suitable for commercial timber use. Therefore, logging often happens in the currently designated as suitable timberlands, which as a result is sufficient to cause rather dramatic changes in landscape structure. These can be proved by the fact that more than $60 \%$ of the total area changed has been converted into other land cover (shrub land, minor forest, no standing forest and non-forest) in all the zones (Table A1). Therefore, the increase in other land cover was partly caused by frequent regeneration failures or time-lagged regenerations following clear-cut logging in the study area. This implies that both road network extensions and forest management practices lead to the increasing of landscape degradation in all the zones, with a higher change rate in the REZ in the study area.

Several indices have been developed to quantify the influence of road disturbance on landscape structure (Mcgarigal et al., 2001; Liu et al., 2014). Most of the current indices focus on habitat fragmentation, isolation, connection or heterogeneity separately, without joint consideration of comprehensive evaluation of these landscape metrics. In this study, LDI, an approach that combines these measures of landscape metrics, was employed to examine the disturbance of road network on landscape. An expected outcome was that the LDI in the REZ was higher than that of the NREZ, and showed an aggravated influence on the forest landscape in the REZ during the study period. Thus, in the REZ, habitat fragmentation may switch from being predominantly internally driven (i.e., logging) to being predominantly externally driven (i.e., road construction). Simultaneously, remnant patches become more and more isolated, thereby resulting in further ecological degradation across the landscapes.

These findings are consistent with other studies from the Rocky Mountains (Reed et al., 1996; Mcgarigal et al., 2001) and the north-central Wyoming (Tinker et al., 1998), which documented that forests were more highly fragmented from roads than from 
clear-cuts. However, we also found that the change ratios of some landscape metrics were higher in the NREZ than in the REZ, these can be explained by the following reasons other than logging mentioned above: (1) Roads provide access and allow landscape pattern to change during the construction and in the early stage, however these changes may be constrained by environmental factors such as topography in the later period after road been built (Hawbaker et al., 2005). In this case, land use changes near roads may be mediated by the constrain of the topographic feature prevailed with the mountain terrain in the study area; (2) a large portion of forest buffer belts were designed for various ecological purpose (e.g. conservation of water and soil, prevention of traffic noise, protection of slope and greening of road), where logging and constructing cannot occur frequently.

\section{Extensions and limitations}

As described by different authors, the simple landscape metrics, e.g., NP, ED, PD and AREA_MN, are the most suitable indices to analyze landscape structure (Frohn and Hao, 2006; Š́mová and Gdulová, 2012), so the cutting and fragmentizing effect of road networks on landscape can be revealed from the changes of such landscape metrics (Sowińska-Świerkosz and Soszyński, 2014). The ED is among a positive index identifying the level of provision of habitats for alien plants, posing a great threat to the existence of native species. Still more important is the dissecting effect of road network, the ED value has also been proven to be crucial for local hydrologic and erosion effects and downstream peak-flow and sediment impacts (Forman, 1998; Uuemaa et al., 2009). In our case, the ED values of REZ were greater than those of NREZ, and the differences incline to be enlarged during the study period. This finding shows that biodiversity in the REZ and water quality in the watersheds has been subjected to severe disturbances by these roads during the study period.

Yet, it is insufficient to assess landscape changes due to road network disturbances within a specific zone/a fixed temporal extent using landscape metrics (Liu et al., 2008), because the extent of REZ may be different for different regions (Forman et al., 2002), moreover, effects of roads on landscape may vary over time (Forman, 1998), while the analysis performed here to the five zones was in the same period and the REZ was at a fixed spatial scale. Such approach does not give answer if a particular stage is up surging for the landscape changes near roads, and if the effects of road network on landscape vary with different extents of REZ. Moreover, the road network has continued to expand over time, and although the overall change has been small, we have failed to consider the impact of new roads on the landscape during the study period.

\section{Conclusions}

Our results showed that there were obvious different forest landscape structures and their dynamics between the NREZ and REZ during the study periods, so the LDI did. In addition, we found that the change ratio of LDI value in the REZ was much higher than that in the NREZ, while it was versa for some landscape fragmentation indices. This is because the high rate of persistence in area size of each forest category between 2007 and 2015, while a relatively faster transition intra/inter- these cover categories occurred in the NREZ. These results indicate that the potential effects of road network on biodiversity maybe severer than the direct effects of logging, while logging may be also an important factor contributing to the habitat fragmentations in the study area. And it 
also shows the necessity of the landscape classification according to the dominant tree species, which will provide more finer information on forest cover change.

Our result indicated that the level of habitat fragmentation and isolation in the MULREZ was much higher than that of the MONREZ, implying that there exists superimposed effect of the roads on the forest landscape. While, an unexpected outcome of the study was the lowest change ratios of landscape metrics in the MULREZ during the study period. The reasons were still unclear so far as from our study. Therefore, we suggest that further investigations should be carried out for this region and beyond by conducting a gradient analysis with changing road buffer zones and a comparison analysis across time periods (e.g., pre- and post- construction of a road). Furthermore, it is also necessary to further quantify forest landscape structure, such as forest edge dynamic and landscape connectivity, analyze the underlying causes of these habitat changes, and to evaluate the effect of such active forest change in this area on carbon emission, which will help to prevent adverse impacts of human dimensions on biodiversity and climate warming. Finally, understanding how the spatial distribution of road networks affects forest landscape pattern should take at least the following factor into account: control for bias that arises when observable biophysical (e.g., topography) and artificial (e.g., logging and mining) factors affect both which landscapes are in REZ and which are in NREZ.

Acknowledgments. This research was funded by the National Natural Science Foundation of China (No. 41901221 and 31971639), to which we are very grateful. We are also very grateful for the support provided by the Natural Science Foundation of Fujian Province, China (No.2019J01406 and 2019J01430). Finally, many thanks to the Forestry Bureau of Sanyuan District, Fujian Province, China for providing us with a validation dataset.

\section{REFERENCES}

[1] Airey, T. (1992): The impact of road construction on the spatial characteristics of hospital utilization in the Meru district of Kenya. - Social Science \& Medicine 34(10): 11351146.

[2] Angelstam, P., Khaulyak, O., Yamelynets, T., Mozgeris, G., Naumov, V., Chmielewski, T. J., Elbakidze, M., Manton, M., Prots, B., Valasiuk, S. (2017): Green infrastructure development at European Union's eastern border: effects of road infrastructure and forest habitat loss. - Journal of Environmental Management 193: 300-311.

[3] Arnold, G. W., Weeldenburg, J. R., Ng, V. M. (1995): Factors affecting the distribution and abundance of Western grey kangaroos (Macropus fuliginosus) and euros (M. Robustus) in a fragmented landscape. - Landscape Ecology 10(2): 65-74.

[4] Benítez-López, A., Alkemade, R., Verweij, P. A. (2010): The impacts of roads and other infrastructure on mammal and bird populations: a meta-analysis. - Biological Conservation 143(6): 1307-1316.

[5] Bordadeágua, L., Navarro, L., Gavinhos, C., Pereira, H. M. (2011): Spatio-temporal impacts of roads on the persistence of populations: analytic and numerical approaches. Landscape Ecology 26(2): 253-265.

[6] Carnus, J. M., Parrotta, J., Brockerhoff, E., Arbez, M., Jactel, H., Kremer, A., Lamb, D., O'Hara, K., Walters, B. (2006): Planted forests and biodiversity. - Journal of Forestry 104(2): 65-77.

[7] Coffin, A. W. (2007): From roadkill to road ecology: a review of the ecological effects of roads. - Journal of Transport Geography 15(5): 396-406. 
[8] Eigenbrod, F., Hecnar, S. J., Fahrig, L. (2008): Accessible habitat: an improved measure of the effects of habitat loss and roads on wildlife populations. - Landscape Ecology 23(2): 159-168.

[9] Forman, R. T. T. (1998): Road ecology: a solution for the giant embracing us. Landscape Ecology 13(4): III-V.

[10] Forman, R. T. T., Reineking, B., Hersperger, A. M. (2002): Road traffic and nearby grassland bird patterns in a suburbanizing landscape. - Environmental Management 29(6): 782-800.

[11] Freudenberger, L., Hobson, P. R., Rupic, S., Pe Er, G., Schluck, M., Sauermann, J., Kreft, S., Selva, N., Ibisch, P. L. (2013): Spatial road disturbance index (SPROADI) for conservation planning: a novel landscape index, demonstrated for the State of Brandenburg, Germany. - Landscape Ecology 28(7): 1353-1369.

[12] Frohn, R. C., Hao, Y. (2006): Landscape metric performance in analyzing two decades of deforestation in the Amazon Basin of Rondonia, Brazil. - Remote Sensing of Environment 100(2): 237-251.

[13] Fu, W., Liu, S., Degloria, S. D., Dong, S., Beazley, R. (2010): Characterizing the "fragmentation-barrier" effect of road networks on landscape connectivity: a case study in Xishuangbanna, Southwest China. - Landscape \& Urban Planning 95(3): 122-129.

[14] Geneletti, D. (2003): Biodiversity impact assessment of roads: an approach based on ecosystem rarity. - Environmental Impact Assessment Review 23(3): 343-365.

[15] Gibbs, J. P., Steen, D. A. (2010): Trends in sex ratios of turtles in the united states: implications of road mortality. - Conservation Biology 19(2): 552-556.

[16] Gutiérrez, J., Urbano, P. (1996): Accessibility in the European Union: the impact of the trans-European road network. - Journal of Transport Geography 4(1): 15-25.

[17] Hansen, M., Potapov, P., Margono, B., Stehman, S., Turubanova, S., Tyukavina, A. (2014): Response to comment on "High-resolution global maps of 21st-century forest cover change". - Science 342(6187): 850-853.

[18] Hargis, C. D., Bissonette, J. A., David, J. L. (1998): The behavior of landscape metrics commonly used in the study of habitat fragmentation. - Landscape Ecology 13(3): 167186.

[19] Hawbaker, T. J., Radeloff, V. C., Hammer, R. B., Clayton, M. K. (2005): Road density and landscape pattern in relation to housing density, and ownership, land cover, and soils. - Landscape Ecology 20(5): 609-625.

[20] Heilman, G. E., Strittholt, J. R., Slosser, N. C., Dellasala, D. A. (2002): Forest fragmentation of the Conterminous United States: assessing forest intactness through road density and spatial characteristics. - Bioscience 52(5): 411-422.

[21] Jaeger, J. A. G., Schwarzvon Raumer, H. G., Esswein, H., Müller, M., Schmidtlüttmann, M. (2007): Time series of landscape fragmentation caused by transportation infrastructure and urban development: a case study from Baden-Württemberg, Germany. - Ecology \& Society 12(1): 181-194.

[22] Karadağ, A. A., Şenik, B. (2019): Landscape sensitivity analysis as an ecological key: the case of Duzce, Turkey. - Applied Ecology and Environmental Research 17: 1427714296.

[23] Li, T., Shilling, F., Thorne, J., Li, F., Schott, H., Boynton, R., Berry, A. M. (2010): Fragmentation of China's landscape by roads and urban areas. - Landscape Ecology 25(6): 839-853.

[24] Liang, J., Liu, Y., Ying, L., Li, P., Xu, Y., Shen, Z. (2014): Road impacts on spatial patterns of land use and landscape fragmentation in three parallel rivers region, Yunnan Province, China. - Chinese Geographical Science 24(1): 15-27.

[25] Lindenmayer, D. B., Margules, C. R., Botkin, D. B. (2000): Indicators of biodiversity for ecologically sustainable forest management. - Conservation Biology 14(4): 941-950.

[26] Liu, S., Dong, Y., Deng, L. I., Liu, Q. I., Zhao, H., Dong, S. (2014): Forest fragmentation and landscape connectivity change associated with road network extension and city 
expansion: a case study in the Lancang River Valley. - Ecological Indicators 36(36): 160168.

[27] Liu, S. L., Cui, B. S., Dong, S. K., Yang, Z. F., Yang, M., Holt, K. (2008): Evaluating the influence of road networks on landscape and regional ecological risk - a case study in Lancang River Valley of Southwest China. - Ecological Engineering 34(2): 91-99.

[28] Mcgarigal, K., Marks, B. J. (1995): FRAGSTATS: spatial pattern analysis program for quantifying landscape structure. - General Technical Report Pnw 351.

[29] Mcgarigal, K., Romme, W. H., Crist, M., Roworth, E. (2001): Cumulative effects of roads and logging on landscape structure in the San Juan Mountains, Colorado (USA). Landscape Ecology 16(4): 327-349.

[30] Mcintyre, N. E. (1995): Effects of forest patch size on avian diversity. - Landscape Ecology 10(2): 85-99.

[31] Mehdipour, N., Fakheran, S., Soffianian, A., Pourmanafi, S. (2019): Road-induced fragmentation and the environmental value of roadless areas in a partly protected landscape in central Iran. - Environmental Monitoring and Assessment 191: 461.

[32] Moser, B., Jaeger, J., A. G., Tappeiner, U. E., Eiselt, B. (2007): Modification of the effective mesh size for measuring landscape fragmentation to solve the boundary problem. - Landscape Ecology 22(3): 447-459.

[33] Patarasuk, R. (2013): Road network connectivity and land-cover dynamics in Lop Buri province, Thailand. - Journal of Transport Geography 28: 111-123.

[34] Peng, Y. (2019): Influence of environmental landscape structure on the distribution features of plant communities in green parks. - Applied Ecology and Environmental Research 17: 14599-14609.

[35] Psaralexi, M. K., Votsi, N. E. P., Selva, N., Mazaris, A. D., Pantis, J. D. (2017): Importance of roadless areas for the European Conservation Network. - Frontiers in Ecology and Evolution 5: 2.

[36] Redo, D. J., Grau, H. R., Aide, T. M., Clark, M. L. (2012): Asymmetric forest transition driven by the interaction of socioeconomic development and environmental heterogeneity in Central America. - Proceedings of the National Academy of Sciences 109(23): 88398844.

[37] Reed, R. A., Johnson-Barnard, J., Baker, W. L. (1996): Fragmentation of a forested Rocky Mountain landscape, 1950-1993. - Biological Conservation 75(3): 267-269, 271277.

[38] Ren, Y., Wei, X., Zhang, L., Cui, S., Chen, F. (2011): Potential for forest vegetation carbon storage in Fujian Province, China, determined from forest inventories. - Plant \& Soil 345(1/2): 125-140.

[39] Selva, N., Kreft, S., Kati, V., Schluck, M., Jonsson, B. G., Mihok, B., Okarma, H., Ibisch, P. L. (2011): Roadless and low-traffic areas as conservation targets in Europe. Environmental Management 48(5): 865-877.

[40] Šímová, P., Gdulová, K. (2012): Landscape indices behavior: a review of scale effects. Applied Geography 34: 385-394.

[41] Sowińska-Świerkosz, B. N., Soszyński, D. (2014): Landscape structure versus the effectiveness of nature conservation: Roztocze region case study (Poland). - Ecological Indicators 43(43): 143-153.

[42] Spooner, P. G., Lunt, I. D., Okabe, A., Shiode, S. (2004): Spatial analysis of roadside Acacia populations on a road network using the network K-function. - Landscape Ecology 19(5): 491-499.

[43] Stephens, S. S., Wagner, M. R. (2007): Forest plantations and biodiversity: a fresh perspective. - Journal of Forestry 105(6): 307-313.

[44] Syrbe, R. U., Walz, U. (2012): Spatial indicators for the assessment of ecosystem services: providing, benefiting and connecting areas and landscape metrics. - Ecological Indicators 21(3): 80-88. 
[45] Tinker, D. B., Resor, C. A. C., Beauvais, G. P., Kipfmueller, K. F., Fernandes, C. I., Baker, W. L. (1998): Watershed analysis of forest fragmentation by clearcuts and roads in a Wyoming forest. - Landscape Ecology 13(3): 149-165.

[46] Trakhtenbrot, A., Ran, N., Perry, G., Richardson, D. M. (2005): The importance of LongDistance dispersal in biodiversity conservation. - Diversity \& Distributions 11(2): 173181.

[47] Turner, M. G., Gardner, R. H., O'Neill, R. V. (2003): Landscape ecology in theory and practice. - Geography 83(5): 479-494.

[48] Uuemaa, E., Antrop, M., Roosaare, J., Marja, R., Mander, Ü. (2009): Landscape metrics and indices: an overview of their use in landscape research. - Living Reviews in Landscape Research 3(1): 1-28.

[49] Wang, J., Cui, B. S., Liu, S. L., Dong, S. K., Wei, G. L., Liu, J. (2007): Effects of road networks on ecosystem service value in the Longitudinal Range-Gorge Region. - Chinese Science Bulletin 52(2 Suppl.): 180-191.

[50] Wimberly, M. C., Ohmann, J. L. (2004): A multi-scale assessment of human and environmental constraints on forest land cover change on the Oregon (USA) coast range. - Landscape Ecology 19(6): 631-646.

[51] Xie, X., Wang, Q., Dai, L., Su, D., Wang, X., Qi, G., Ye, Y. (2011): Application of china's national forest continuous inventory database. - Environmental Management 48(6): 1095-1106.

[52] Zhang, X. H., Huang, Q. L., Zhang, C. (2010): Analysis of forest landscape dynamics based on Forest Landscape Restoration: a case study of Yong'an city, Fujian province, China. - European Journal of Forest Research 129(5): 975-980.

[53] Zhu, M., Jiangang, X. U., Jiang, N., Jianlong, L. I., Fan, Y. (2006): Impacts of road corridors on urban landscape pattern: a gradient analysis with changing grain size in Shanghai, China. - Landscape Ecology 21(5): 723-734.

\section{APPENDIX}

Table A1. Landscape transfer matrix between 2007 and 2015

\begin{tabular}{c|c|c|c|c|c|c|c|c|c|c|c}
\hline \multirow{2}{*}{2007} & \multicolumn{10}{c}{ 2015 } \\
\cline { 2 - 11 } & Landscape & FI & PI & RT & SW & HW & EU & BA & ET & OL & \% (2007) \\
\hline \multirow{5}{*}{ FI } & WL & 93.1 & 0.1 & 0.1 & 0.0 & 0.3 & 0.0 & 0.7 & 0.0 & 5.8 & 34.1 \\
& NREZ & 93.3 & 0.1 & 0.1 & 0.0 & 0.2 & 0.0 & 0.6 & 0.0 & 5.7 & 33.6 \\
& REZ & 92.1 & 0.0 & 0.0 & 0.0 & 0.4 & 0.0 & 1.3 & 0.0 & 6.2 & 39.2 \\
& MONREZ & 92.0 & 0.0 & 0.0 & 0.0 & 0.4 & 0.0 & 1.4 & 0.0 & 6.2 & 39.9 \\
& MULREZ & 93.8 & 0.0 & 0.0 & 0.0 & 0.0 & 0.0 & 0.1 & 0.0 & 6.2 & 26.1 \\
\hline \multirow{6}{*}{ PI } & WL & 4.9 & 92.6 & 0.0 & 0.0 & 0.5 & 0.0 & 0.4 & 0.0 & 1.6 & 13.1 \\
& NREZ & 5.3 & 92.4 & 0.0 & 0.0 & 0.6 & 0.0 & 0.4 & 0.0 & 1.3 & 12.9 \\
& REZ & 1.5 & 94.3 & 0.0 & 0.0 & 0.0 & 0.0 & 0.0 & 0.0 & 4.2 & 15.1 \\
& MONREZ & 1.6 & 94.0 & 0.0 & 0.0 & 0.0 & 0.0 & 0.0 & 0.0 & 4.4 & 14.9 \\
& MULREZ & 0.0 & 99.0 & 0.0 & 0.0 & 0.0 & 0.0 & 0.0 & 0.0 & 1.0 & 18.0 \\
\hline \multirow{6}{*}{ RT } & WL & 6.3 & 0.0 & 91.4 & 0.0 & 0.0 & 0.0 & 0.0 & 0.0 & 2.2 & 0.1 \\
& NREZ & 3.9 & 0.0 & 90.4 & 0.0 & 0.0 & 0.0 & 0.0 & 0.0 & 5.7 & 0.1 \\
& REZ & 7.9 & 0.0 & 92.1 & 0.0 & 0.0 & 0.0 & 0.0 & 0.0 & 0.0 & 0.9 \\
& MONREZ & 6.8 & 0.0 & 93.2 & 0.0 & 0.0 & 0.0 & 0.0 & 0.0 & 0.0 & 0.9 \\
& MULREZ & 100.0 & 0.0 & 0.0 & 0.0 & 0.0 & 0.0 & 0.0 & 0.0 & 0.0 & 0.2 \\
\hline
\end{tabular}




\begin{tabular}{|c|c|c|c|c|c|c|c|c|c|c|c|}
\hline \multirow{5}{*}{ ST } & WL & 0.7 & 1.9 & 0.5 & 92.2 & 1.6 & 2.2 & 0.2 & 0.0 & 0.7 & 0.7 \\
\hline & NREZ & 0.8 & 1.8 & 0.0 & 93.1 & 0.9 & 2.6 & 0.3 & 0.0 & 0.5 & 0.6 \\
\hline & REZ & 0.1 & 2.2 & 3.2 & 86.9 & 6.3 & 0.0 & 0.0 & 0.0 & 1.4 & 1.0 \\
\hline & MONREZ & 0.1 & 2.3 & 3.4 & 86.1 & 6.6 & 0.0 & 0.0 & 0.0 & 1.5 & 1.0 \\
\hline & MULREZ & 0.0 & 0.0 & 0.0 & 100.0 & 0.0 & 0.0 & 0.0 & 0.0 & 0.0 & 1.2 \\
\hline \multirow{5}{*}{ HW } & WL & 0.8 & 0.3 & 0.0 & 0.0 & 98.6 & 0.0 & 0.1 & 0.0 & 0.2 & 13.8 \\
\hline & NREZ & 0.8 & 0.3 & 0.0 & 0.0 & 98.6 & 0.0 & 0.0 & 0.0 & 0.2 & 14.3 \\
\hline & REZ & 1.0 & 0.0 & 0.0 & 0.0 & 98.0 & 0.0 & 0.2 & 0.2 & 0.6 & 9.4 \\
\hline & MONREZ & 1.1 & 0.0 & 0.0 & 0.0 & 97.9 & 0.0 & 0.2 & 0.2 & 0.7 & 9.2 \\
\hline & MULREZ & 0.1 & 0.0 & 0.0 & 0.0 & 99.9 & 0.0 & 0.0 & 0.0 & 0.0 & 13.0 \\
\hline \multirow{5}{*}{ EU } & WL & 0.0 & 0.0 & 0.0 & 0.0 & 0.0 & 82.7 & 0.0 & 0.0 & 17.3 & 0.1 \\
\hline & NREZ & 0.0 & 0.0 & 0.0 & 0.0 & 0.0 & 81.0 & 0.0 & 0.0 & 19.0 & 0.1 \\
\hline & REZ & 0.0 & 0.0 & 0.0 & 0.0 & 0.0 & 100.0 & 0.0 & 0.0 & 0.0 & 0.1 \\
\hline & MONREZ & 0.0 & 0.0 & 0.0 & 0.0 & 0.0 & 100.0 & 0.0 & 0.0 & 0.0 & 0.1 \\
\hline & MULREZ & 0.0 & 0.0 & 0.0 & 0.0 & 0.0 & 0.0 & 0.0 & 0.0 & 0.0 & 0.0 \\
\hline \multirow{5}{*}{ BA } & WL & 0.3 & 0.0 & 0.0 & 0.0 & 0.1 & 0.0 & 99.0 & 0.1 & 0.5 & 31.7 \\
\hline & NREZ & 0.3 & 0.1 & 0.0 & 0.0 & 0.1 & 0.0 & 99.0 & 0.0 & 0.5 & 32.8 \\
\hline & REZ & 0.8 & 0.0 & 0.0 & 0.0 & 0.0 & 0.0 & 98.6 & 0.5 & 0.1 & 21.5 \\
\hline & MONREZ & 0.8 & 0.0 & 0.0 & 0.0 & 0.0 & 0.0 & 98.5 & 0.5 & 0.1 & 21.3 \\
\hline & MULREZ & 0.4 & 0.0 & 0.0 & 0.0 & 0.0 & 0.0 & 99.6 & 0.0 & 0.0 & 24.9 \\
\hline \multirow{5}{*}{ ET } & WL & 0.5 & 0.0 & 0.0 & 0.0 & 0.0 & 0.6 & 0.2 & 95.0 & 3.7 & 5.6 \\
\hline & NREZ & 0.6 & 0.0 & 0.0 & 0.0 & 0.1 & 0.6 & 0.2 & 95.3 & 3.3 & 5.1 \\
\hline & REZ & 0.0 & 0.0 & 0.0 & 0.0 & 0.0 & 0.8 & 0.2 & 93.6 & 5.3 & 10.1 \\
\hline & MONREZ & 0.0 & 0.0 & 0.0 & 0.0 & 0.0 & 0.8 & 0.2 & 93.3 & 5.6 & 10.0 \\
\hline & MULREZ & 0.0 & 0.0 & 0.0 & 0.0 & 0.0 & 0.4 & 0.0 & 98.9 & 0.8 & 11.6 \\
\hline \multirow{5}{*}{ OL } & WL & 1.8 & 0.0 & 0.0 & 0.0 & 0.1 & 0.0 & 0.0 & 0.0 & \begin{tabular}{|l|}
98.1 \\
\end{tabular} & 0.8 \\
\hline & NREZ & 0.0 & 0.0 & 0.0 & 0.0 & 0.0 & 0.0 & 0.0 & 0.0 & 100.0 & 0.6 \\
\hline & REZ & 5.4 & 0.0 & 0.0 & 0.0 & 0.2 & 0.0 & 0.0 & 0.0 & 94.5 & 2.8 \\
\hline & MONREZ & 5.9 & 0.0 & 0.0 & 0.0 & 0.2 & 0.0 & 0.0 & 0.0 & 93.9 & 2.6 \\
\hline & MULREZ & 0.0 & 0.0 & 0.0 & 0.0 & 0.0 & 0.0 & 0.0 & 0.0 & 100.0 & 5.0 \\
\hline \multirow{5}{*}{$\begin{array}{c}\% \\
(2015)\end{array}$} & WL & 32.7 & 12.2 & 0.1 & 0.6 & 13.8 & 0.1 & 31.7 & 5.4 & 3.4 & 100.0 \\
\hline & NREZ & 32.2 & 12.0 & 0.1 & 0.6 & 14.2 & 0.1 & 32.7 & 4.9 & 3.1 & 100.0 \\
\hline & REZ & 36.8 & 14.2 & 0.8 & 0.9 & 9.4 & 0.2 & 21.7 & 9.6 & 6.3 & 100.0 \\
\hline & MONREZ & 37.5 & 14.1 & 0.9 & 0.9 & 9.3 & 0.2 & 21.6 & 9.4 & 6.2 & 100.0 \\
\hline & MULREZ & 24.8 & 17.8 & 0.0 & 1.2 & 13.0 & 0.0 & 24.8 & 11.5 & 6.9 & 100.0 \\
\hline
\end{tabular}

Fir (FI), Pine (PI), Rare tree (RT), Softwood (SW), Hardwood (HW), Eucalyptus (EU), Bamboo (BA), Economic tree (ET) and other land cover $(\mathrm{OL})$ 